\title{
Sweat Gland
}

National Cancer Institute

\section{Source}

National Cancer Institute. Sweat Gland. NCI Thesaurus. Code C33712.

The small coiled tubes in the skin that produce and secrete sweat. 